\title{
Barriers to infection prevention and control (IPC) practice among nurses at Bindura Provincial Hospital, Zimbabwe
}

\author{
${ }^{1}$ Chipfuwa Tirivanhu, ${ }^{2}$ Manwere Ancia, ${ }^{3}$ Shayamano Petronella \\ ( ${ }^{1}$ Department of Health Sciences, Bindura University of Science Education, Zimbabwe) \\ $\left({ }^{2}\right.$ Department of Health Sciences, Bindura University of Science Education, Zimbabwe) \\ ( 3 Outpatients Department, Shashi Private Hospital, Bindura, Zimbabwe)
}

\begin{abstract}
The purpose of the study was to determine barriers to infection prevention and control (IPC) practice among nurses at Bindura Provincial Hospital. A descriptive research design was used. Simple random sampling method was used to select 50 nurses. A structured self-administered questionnaire was used to collect data. The study findings revealed that lack of knowledge was one of the barriers to IPC practice as only 14 (28\%) of the nurses had excellent knowledge on infection control principles. Utilization of the infection control manual was poor as 21 (42\%) nurses did not utilize the infection control manual, either because they did not know about it $12(24 \%)$ or it was not available 9 (18\%). Infection control workshops were poorly organized as $68 \%$ of the nurses did not attend any workshop on IPC which contributed to poor IPC practice. Other factors impeding infection control practice were lack of time and resources. Therefore, there is need by policy makers to provide in-service education on infection control principles on regular basis to all nurses to keep them updated with current knowledge as well as provision of adequate human and material resources.
\end{abstract}

Key words: Barriers, Infection Prevention \& Control, Nosocomial infections, Practice, Sterile technique

\section{Introduction}

The primary objective of infection prevention and control (IPC) is to prevent the spread of infection in health care facilities and settings; thereby assisting health care workers in the provision of quality health care. Infection prevention and control policies, guidelines and procedures are required in the monitoring, surveillance, and control of infections in health care facilities and settings. The Manual of Infection Prevention and Control Policies and Guidelines was developed to provide a central reference for all health care facilities/settings and health care workers. The policies and guidelines can be expected to change in response to new knowledge and technology. Their adaption/adoption does not guarantee implementation by health care workers. The reduction of nosocomial infection risks depends largely on the actual performance of correct patient care practices. Health care workers may be motivated to follow these practices if adequate infrastructure and supplies are provided, they are appropriately supervised, and given adequate training followed by periodic in-service education (Reid, 2001).

According to the World Health Organization (WHO), (2001) the burden of nosocomial infections has been seen to be substantial in developed countries where it affects $5-15 \%$ of hospitalized patients in regular wards and in as many as 50\% or more in intensive care units. In developing countries, mostly African countries the magnitude of the problem is high due to overcrowding and understaffing in hospitals. This leads to inadequate infection control practices. Lack of infection control policies, guidelines and trained professionals also add to the extent of the problem (WHO, 2001). The most common nosocomial infections in Africa are urinary tract infections, surgical site infections, hospital acquired pneumonia and health care associated septicaemia (First African Conference on Infection Prevention control, 2009). The World Health Organization (2009), estimate that 5\%-10\% of patients, they acquired one or more infection in health facilities, the risk being 2-10 times higher in developing countries.

Nurses play an important role in health delivery service worldwide, Zimbabwe in particular. Their role is critical in prevention and control of infection spread. Nurses are at the fore front of patient care hence facilitating the spread of infection. This is particularly so for junior nurses who are doing most of the work in the wards because of acute shortage of experienced qualified nurses in the country. The nurses may do the work hurriedly and in the process, fail to follow correct measures of preventing infection, thereby putting the patient at risk of acquiring nosocomial infection.

Fifteen percent (15\%) of hospital admissions acquire nosocomial infection and the susceptibility to infection has been associated with the use of invasive devices and negligent infection control practice which contribute to the necessity of implementing control measures, (Creedon, 2005). According to Bindura Provincial Hospital (BPH) Infection Control Report (2013), unpublished 14 (1.08\%) of the patients contacted nosocomial infections in the female ward, $6(0,38 \%)$ in the male ward, $3(0.2 \%)$ in the children's ward and the intensive care unit recorded the highest nosocomial infections of 50 (27.62\%). The World Health Organisation Guidelines 
(2001) states that nosocomial infections should never be found in hospitals if proper infection control practice is carried out. Therefore, there is need to determine whether these cases of nosocomial infections are a results of barriers impeding the nurses at Bindura Provincial Hospital from executing proper infection prevention and control practices.

Smith (2009) reported that the factors which impede nurses from practising IPC were: lack of knowledge on IPC, lack of time to deliver proper infection control due to low nurse patient ratio, lack of equipment and forgetfulness. Furthermore, Dyer (2010) also highlighted lack of resources as a factor impeding nurses from proper infection control practice. He found out that most nosocomial infections in Egyptian hospitals result from lack of resources such as gloves and face masks.

Swanson (2002) indicated that lack of knowledge is a major factor that impedes in proper infection control practice. He found that most of the nurses have no adequate input on infection control principles. He further suggests that nurses should get some in service training on the principles.

Clark (2011) asserts that nurses have so many factors that impede them from proper practice of infection control principles. In her study on infection control problems and solutions, she found that $36 \%$ of the nurses had problems in forgetting to practice the sterile technique and $44 \%$ lacked knowledge on infection control principles.

A study by Had (2000) revealed that the overall knowledge was below $80 \%$ and reflected that nurses really need to be educated on infection prevention and control. Another study by Birgani (2002) revealed that Iran nurses at Ahvaz hospital had poor knowledge on IPC. Lebrague et al (2012) indicated that the more knowledgeable the nurses are, the more skilful they are in practice of sterile technique. This therefore reinforce the importance of in-service training among nurses to keep them updated with new trends and developments of infection control and sterile technique principles in order to become increasingly efficient and effective at preventing nosocomial infections.

\subsection{Purpose of the study}

The purpose of the study was to determine barriers to infection prevention and control practice among nurses at Bindura Provincial Hospital.

\subsection{Objective}

- To determine the barriers to infection prevention and control practice among nurses at Bindura Provincial Hospital.

\section{-}

\subsection{Conceptual Framework}

This study utilised Florence Nightingale theory on infection control (1854). The theory provides an explanation as to why it is important to carry out infection control measures such as damp dusting, use of sterile technique during procedures and use of personal protective equipment. Nightingale was the first nurse to identify the relationship between nursing and infection control (Kamisky, 2004). The conditions in the hospitals were deplorable hence her observations led her to believe that improving hygiene conditions would decrease the number of deaths. Lawrence, chairperson of the infection control nurses association (ICNA) believed that Nightingale was probably the first infection control nurse without actually realising it (Elliot, 2000). Today nurses are key players in the fight to ensure the survival of infection control practices. This can be achieved through observing proper infection control and sterile technique principles as well as continuous education on infection control through in-service training and induction courses.

\subsection{Design and Sample}

\section{Methodology}

This study used a descriptive research design. A sample of 50 nurses was selected using simple random sampling. The inclusion criteria included all Registered General Nurses (RGN) working in the female, male, children and maternity wards including theatre at Bindura Provincial Hospital. Questionnaires were developed in English from relevant literature specifically for this study. Each questionnaire had three sections: Section A: Demographic data, Section B comprised of nurses' knowledge of infection control and then Section C the practice of sterile technique principles. Knowledge of infection prevention and control was measured using scoring. The highest possible score was 20 . Those who scored below 10 had poor knowledge, those who scored 10 to 14 had moderate knowledge and those who scored 15 to 20 had excellent knowledge. The permission to carry out the study was granted by the Medical Superintendent of Bindura Provincial Hospital, Research Ethics Board of Bindura University of Science Education. 


\subsection{Data Collection and Analysis}

Code numbers were used on the questionnaires to ensure confidentiality. The forms were locked up in the cabinet; only the investigators had access to the data collected. The questionnaires were destroyed after data analysis. Five nurses who met the inclusion criteria answered the questionnaires to determine clarity of the terms and consistency of responses at Shashi Hospital in the pilot study. Possible data analysis procedures were tested in the pilot study. No modifications and corrections were made after the pilot study. Statistical Package for Social Science (SPSS version 16; 2012) was used to analyse the data.

\subsection{Socio-demographic Data}

\section{Results and Findings}

The majority of the respondents $24(48 \%)$ were in the age category of $26-35$ years. Six (12\%) of the respondents were charge nurses, $13(26 \%)$ were junior nurses and 31(62\%) were senior nurses. Eleven (22\%) of the respondents had been in the profession for a period of 1-2 years, 18(36\%) a period of 3-10 years and $21(42 \%)$ a period of more than 10 years.

Table 1: Total knowledge scores

\begin{tabular}{|l|l|l|}
\hline Knowledge level & Frequency (n) & Score out of 20 \\
\hline Poor knowledge & $11(22 \%)$ & Below 10 \\
\hline Moderate knowledge & $25(50 \%)$ & $10-14$ \\
\hline Excellent knowledge & $14(28 \%)$ & $15-20$ \\
\hline
\end{tabular}

Table 1 shows that $11(22 \%)$ of the respondents had poor knowledge level of infection control principles by scoring a score of below 10, 25(50\%) had moderate knowledge by scoring a score of 10 to 14 and $14(28 \%)$ had excellent knowledge of infection control principles by scoring a score of 15 to 20 .

Figure 1: Attendances of infection control workshops $(\mathrm{N}=50)$

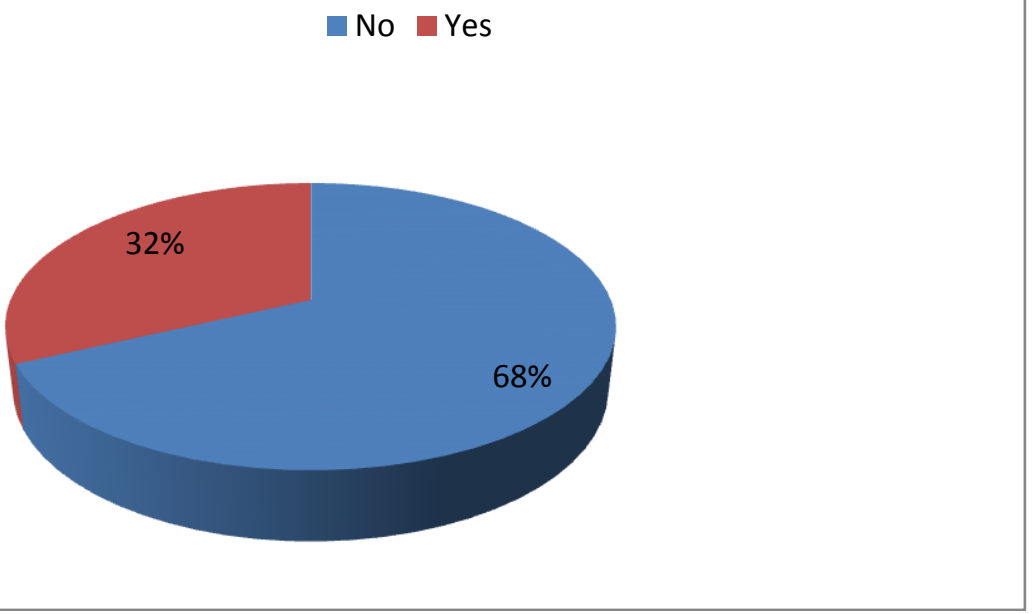

Fig 1 shows that the majority of the respondents $34(68 \%)$ had never attended any infection control workshop and $16(32 \%)$ had attended the workshop.

Table 2: Input from IPC guideline manual \& IPC Nurse $(\mathrm{N}=50)$

\begin{tabular}{|l|l|l|}
\hline Variable & Frequency (n) & Percentage (\%) \\
\hline Presence of Infection Prevention \& Control (IPC) guideline manual & & 24 \\
\hline Do not know & 12 & 18 \\
\hline No & 9 & 58 \\
\hline Yes & 29 & \\
\hline Presence of Infection Prevention \& Control Nurse & & 10 \\
\hline Do not know & 5 & 10 \\
\hline No & 5 & 80 \\
\hline Yes & 40 & \\
\hline Input from Infection Prevention \& Control Nurse & & \\
\hline Never & 27 & 54 \\
\hline Sometimes & 20 & 40 \\
\hline Most of time & 3 & 6 \\
\hline Total & $\mathbf{5 0}$ \\
\hline
\end{tabular}


Table 2 shows that $12(24 \%)$ of the respondents did not know whether an infection control guideline manual is available in their ward, $9(18 \%)$ indicated that they did not have and $29(58 \%)$ indicated that they had the manual in their ward. Five $(10 \%)$ of the respondents indicated that they did not know if they had an infection control nurse at the hospital, 5(10\%) indicated they did not have and 40(80\%) indicated that they had. Furthermore, $27(54 \%)$ of the respondents reported that never received input from the infection control nurse, 20 $(40 \%)$ received input sometimes and $3(6 \%)$ received input most of the time.

Table 3: Association between status and attendance of infection control workshops $(\mathrm{N}=50)$

\begin{tabular}{|l|l|l|l|}
\hline \multirow{2}{*}{ Professional status } & Attendance of infection control workshops & Total \\
\cline { 2 - 4 } & No & Yes & 6 \\
\hline Sister in charge & 1 & 5 & 13 \\
\hline Junior nurse & 12 & 1 & 31 \\
\hline Senior nurse & 21 & 10 & $\mathbf{5 0}$ \\
\hline Total & $\mathbf{3 4}$ & $\mathbf{1 6}$ & \\
\hline
\end{tabular}

Table 3 shows that $5(83 \%)$ of the sisters in charge had attended infection control workshops, $1(8 \%)$ of the junior nurses had attended and $10(32 \%)$ of the senior nurses had attended the workshop. There was a significance level value ( $\mathrm{p}$-value) of $0.001(\mathrm{p}<0.05)$.

Table 4: Association between years in nursing profession and attendance of infection control workshops $(\mathrm{N}=$ 50)

\begin{tabular}{|l|l|l|l|}
\hline \multirow{2}{*}{ Years in profession } & \multicolumn{2}{|l|}{ Attendance of infection control workshops } \\
\cline { 2 - 4 } & No & Yes & Total \\
\hline $1-2$ years & 11 & 0 & 11 \\
\hline $3-10$ years & 14 & 4 & 18 \\
\hline Above 10 years & 9 & 12 & 21 \\
\hline Total & $\mathbf{3 4}$ & $\mathbf{1 6}$ & $\mathbf{5 0}$ \\
\hline
\end{tabular}

Table 4 shows that $4(22 \%)$ of the nurses who had been in the profession for 3-10 years had attended an infection control workshop and $12(57 \%)$ with above 10 years in profession had attended the workshop. There was a significance level value ( $\mathrm{p}$-value) of $0.001(\mathrm{p}<0.05)$.

Table 5: Factors impeding proper infection control practice $(\mathrm{N}=50)$

\begin{tabular}{|l|l|l|}
\hline $\begin{array}{l}\text { Factors impeding infection control } \\
\text { practice }\end{array}$ & Frequency (n) & Percentage (\%) \\
\hline Lack of knowledge & 12 & 24 \\
\hline Lack of time & 13 & 26 \\
\hline Lack of equipment & 8 & 16 \\
\hline Forgetfulness & 5 & 10 \\
\hline Lack of resources & 12 & 24 \\
\hline Total & $\mathbf{5 0}$ & $\mathbf{1 0 0}$ \\
\hline
\end{tabular}

Table 5 shows that $12(24 \%)$ of the respondents indicated lack of knowledge as a factor that impeded them from proper infection control practice, $13(26 \%)$ indicated lack of time, $8(16 \%)$ indicated lack of equipment, $5(10 \%)$ indicated forgetfulness as a factor and $12(24 \%)$ indicated lack of resources as a factor impeding them.

\section{Discussion}

The majority of the nurses (58\%) had less than 10 years in the nursing profession and these are mostly junior nurses $(26 \%)$ and they are the ones with poor knowledge on infection prevention and control. Thirty six (72\%) of the respondents had knowledge of IPC principles score below 14 (which below $80 \%$ of the knowledge scores). This shows that the nurses' knowledge of IPC principles is not adequate which concurs with previous studies by Had (2000) \& Smith (2009). To worsen the problem these junior nurses are the ones doing the nursing care and are deprived of the opportunity to attend workshops.

A quite significant number of nurses $(68 \%)$ did not attend infection control workshops with the majority of these $(97 \%)$ being junior and senior nurses who are always providing day to day nursing care. The results also show that there was poor arrangement of these workshops as a nurse would spent more than 2 years post qualification without having an infection control workshop. A large number of senior nurses (75\%) managed to attend IPC workshops and were expected to give feedback to the junior nurses but this is not the case. This therefore poses a great risk of nosocomial infections as highlighted in a report by WHO (2001). Therefore, there is need for workshops to be planned periodically to equip the nurses with knowledge on IPC. This is supported by Reid (2001) who suggested that nurses should get in- service training to gain knowledge on IPC. 
There was quite a large number $5(10 \%)$ who did not know that there was an infection control nurse (ICN) and another $5(10 \%)$ reported that there was no infection control nurse. Furthermore, 27(54\%) of the respondents did not get input from the infection control nurse, with 20(40\%) reporting that they sometimes get it. Additionally, 21(42\%) of the respondents did not utilize the infection control manual, either because they did not know about it $12(24 \%)$ or it was not available $9(18 \%)$. These results are in contrast with Malan who indicated that $89 \%$ were familiar with contents whilst only $11 \%$ were not. Therefore the infection control nurse should periodically teach the nurses in practice and the infection control manual should be present in each ward. The nurses should be inducted on the use and importance of the manual. Other factors impeding IPC practices reported are: lack of resources and time which is consistent with what was reported in previous studies by Smith (2009), Dyer (2010), Swanson (2002) \& Clark (2011).

\subsection{Nursing Education}

\section{Nursing Implications}

- The findings of this study are going to help in designing of the nursing education curriculum. It should include information on infection control so that the students can gain in-depth knowledge on infection prevention and control principles.

- In-service education should be provided on infection control on regular basis as a measure to reinforce the knowledge of nurses on infection control.

\subsection{Nursing Administration}

- The policy makers should make sure infection prevention and control policy manuals are made available to every nurse.

- Resources such as disinfectants should be made available for the nurses to practice proper infection control.

- There is need for an improvement on the nurse patient ratio through recruitment of more nurses thus addressing the reason of nurses lacking enough time to practice proper infection prevention and control principles.

\subsection{Nursing Research}

- The research findings are going to provide basis for other researchers who would want to carry out further research on infection prevention and control principles.

\section{Conclusion}

The study revealed that the majority of junior nurses lack knowledge of infection control principles. Factors impeding nurses from proper infection prevention and control practice which included lack of knowledge, forgetfulness, lack of time and lack of resources were identified. Therefore, there is need for policy makers and administrators to provide both human and material resources as well as provide timely and well planned in-service training to the nurses.

\section{References}

[1] Reid V.U.(2001). Infection Prevention and Control Policies and Guidelines. Retrieved on 15 February 2013 from http://www.uow.edu.au/content/groups/public/@web/@health/...

[2] World Health Organisation (WHO) (2001). Practical guidelines for Infection Control in the Health Care. Retrieved 15 January 2013 from www.searo.who.int/.../infectioncontrolfullmanual.pdf.

[3] First African Conference Infection Control Prevention Report (2009). Retrieved January 26, 2013 from http://whqlibdoc. who.int/publications/2001/9789241597906eng.pdf.

[4] World Health Organisation (2009). Guidelines on Hygiene in Health Care: First Global Safety Challenge: Clean Care is safe care. Retrieved 10 February 2013 from http://www.whqlibdoc.who.int/publications/2009/9789241597906_eng.pdf.

[5] Creedon S. A.(2005). Healthcare Workers' Hand Decontamination Practices: Compliance with Recommended Guidelines, Journal of Advanced Nursing 51(3), 208-216.

[6] Bindura Provincial Hospital Infection Control Report (2013) (unpublished).

[7] Smith J.(2009). Study on factors impeding nurses on infection control practice, University of Calgary. Retrieved on February 28 , 2013 from http://.www.juns.nursing.arizona.edu/articles/fall\%202009/infection\%20conrol.htm.

[8] Dyer I.N.(2010). Attitudes Towards Infection Control. Nursing Update 29(6), 215-225.

[9] Swanson A. (2002). Clean Surgical Wounds: Factors Impeding Infection Control Practice. Nursing Standard 15(2), 174-182

[10] Clark D. Nursing in the community (New York: Appleton and Lange, 2011).

[11] Had A. (2000). Study To Assess Knowledge Of Infection Control Among Egyptian Nurses, Department Of Medicine: Theodor Bilharz Research Institute, Egypt. Retrieved on April 4, 2013 from http://www.ncbi,nih.gov/pubmed/8708223.

[12] Birgani, A.G. (2012), Study to Determine Nurses' Knowledge In Relation To Nosocomial Infection Control, Iran. Retrieved from http://www.cgpublisher.com/proposals/44/index-html.

[13] Lebrague et al (2012). Study on Nurses' Knowledge and Practice of Sterile Technique Principles. Dissertation abstracts international, 54(12), 4346-4352.

[14] Kaminsky P(2004). Everything Is Old Again: An Infection Control Update. Retrieved on May 19, 2013 from http://www.highbeam.com/doc/1P3-681300171.html.

[15] Elliot J(2004). The Multi-Faceted Lady with the Lamp. Retrieved February 10, 2013 from http://www.news.bbc.co.uk/1/hi/health/3943997.stm. 